\section{CÓMO FUNCIONA LA MENTE: LA REPRESENTACIÓN VISUAL DE LOS PROCESOS CEREBRALES}

\author{
Michael Hagner \\ Chair for Science Studies \\ Swiss Federal Institute of Technology \\ ETH Zentrum RAC F 14 \\ Zurich
}

\begin{abstract}
This paper offers an account on the history of visualization, in particular the visualization of brain activity, through a description of different sets of theories and techniques, dating back to the nineteenth century up to the present day, designed to represent mental processes.
\end{abstract}

KEY WORDS: Neuroscience; visualization; neuroimagology.

\section{IMÁGENES DEL CEREBRO}

El debate en torno a la representación cerebral y la localización de los procesos mentales se ha animado recientemente. No porque el debate sobre la relación entre el cerebro y la mente, que siempre fue muy irregular, haya sido enriquecido ahora con planteamientos teóricos particularmente originales. Se trata más bien de planteamientos visuales, basados en un número de técnicas de imagología que trascienden el ámbito de cualquier técnica de visualización conocida hasta ahora en las neurociencias. En la historia de las ciencias humanas, las innovaciones en tecnología de la visualización han influido en la propia percepción de la naturaleza física y moral del hombre. La neuroimagología ha convertido los fenómenos psicológicos en categorías visuales, transformando de este modo su estatus epistémico y cultural. Cuán profundos y prolongados llegarán a ser estos cambios no está claro aún, pero básicamente existen dos escenarios posibles. 0 bien las imágenes del cerebro vendrán a jugar un papel fundamental a la hora de determinar nuestra identidad, al menos en ciertos ámbitos, o bien perderán eventualmente su atractivo, pues contemplar imágenes asociando supuestos estados mentales con ciertas regiones del cerebro resultará a la larga ineficaz si no consiguen proporcionar algún tipo de comprensión más profunda del modo en que se relacionan el estado cerebral y los estados mentales. Aunque tiendo

\section{HOW THE MIND WORKS: THE VISUAL REPRESENTAION OF BRAIN PROCESSES}

RESUMEN: Este trabajo ofrece un repaso de la historia de la visualización de los procesos mentales a través de la descripción de las diferentes tecnologías desarrolladas desde el siglo XIX hasta nuestros dias destinadas a representar la actividad cerebral.

PALABRAS CLAVE: Neurociencia; visualizacion; neuroimagología.

a pensar que la fascinación de estas imágenes terminará mostrando sus límites, el objeto de este artículo es discutir las posibles consecuencias de una antropología basada en imágenes del cerebro".

La tradicional tecnología de rayos $\mathrm{X}$ no aportó ninguna interpretación nueva sobre el funcionamiento del cerebro. Tampoco la tomografía por ordenador, que fue acogida como revolucionaria cuando se desarrolló hace unos cuarenta años y ahora puede ser considerada probablemente como una tecnología transitoria en el paso de la imagología radiológica a la realizada por ordenador. Aunque el desarrollo de la tomografía por ordenador estuvo íntimamente ligado a la decepción del momento respecto a las técnicas radiológicas para la representación del cerebro (Blume, 1992, 159-60), las esperanzas puestas en ella se limitaron al dominio de la medicina clínica y apenas afectó a las neurociencias cognitivas. Con las nuevas técnicas en imagología -FMRT (tomografía de resonancia magnética funcional), PET (tomografía por emisión de positrones) o SPECT (tomografía por emisión de fotón único), por nombrar sólo las más importantes- la situación ha cambiado. Las imágenes del cerebro producidas mediante tales técnicas ocupan páginas enteras en revistas y diarios. Dan la impresión de abrir una ventana nueva hacia el funcionamiento del cerebro y por ende hacia la vida mental del hombre, una impresión que titulares y comentarios se 
encargan de consolidar. En sí misma, semejante retórica no resulta especialmente relevante. Siempre acompaña de un modo u otro a cualquier innovación tecnológica. La introducción de los rayos $X$ al comienzo del siglo XX fue también recibida con una buena dosis de retórica (Cartwright, 1995; Dommann, 2003). Pero la percepción e interpretación culturales que han surgido en relación a la neuroimagología son algo más que una simple fascinación de moda respecto a la nueva visualización de los procesos cerebrales. Conjeturas, ideas y juicios de valor que tienen su origen en el siglo XIX y que, cabría pensar, han estado soterradas durante mucho tiempo, están siendo recuperadas a la hora de interpretar estas imágenes.

Para una mejor comprensión y apreciación de estas imágenes es importante que las situemos en el contexto algo más amplio de otro cambio profundamente arraigado que influyó en la producción de imágenes: la transición de la fotografía ordinaria, basada en principios de óptica, a las imágenes asistidas por ordenador, que ya no se basan en los mismos principios. La técnica conocida como BOLDfMRT (BOLD= Blood-Oxygen-Level-Dependent, dependiente del nivel de oxígeno en la sangre) aprovecha el hecho de que la hemoglobina desoxigenada en los vasos sanguíneos del cerebro sea magnética, mientras que la hemoglobina oxigenada no lo es (Hüsing et al., 2006, 21-50). La aplicación de un campo magnético fuerte permite medir la distribución de los átomos de hidrógeno. Se requiere una complicada operación matemática para transformar los datos obtenidos en una imagen. El término inglés para la imagología, imaging, es muy apropiado para designar este proceso, dado que la imagen no es una simple representación del objeto, sino más bien algo que se elabora. Los datos podrian ser igualmente transformados en una gráfica o en una curva de distribución. Pero esto no tendria el impacto visual de las coloridas imágenes cerebrales, las cuales dan la impresión, algo engañosa, de la evidencia inmediata.

Las nuevas imágenes del cerebro son entonces el resultado de un proceso de elaboración que sin embargo remite a una realidad orgánica. Como la fotografía o la radiología, las nuevas técnicas de imagología requieren de un cuerpo. Esto es lo que las distingue de las imágenes simuladas por ordenador. Como observó Roland Barthes respecto a la fotografía, no se puede negar que "la cosa esté ahi" (Barthes, 1981, 86). Pero, ¿qué es lo que se está midiendo?
Básicamente sólo un pequeño aumento del flujo sanguíneo en una determinada región del cerebro. 0 dicho con más exactitud: la sangre en un punto concreto contiene algo más de oxígeno que en otro. Esto es lo que se ve en el escáner del cerebro. Esta actividad, que es primero medida y luego visualizada, puede estar relacionada con el incremento de la actividad neuronal. En zonas con mayor descarga neuronal, es necesario más oxígeno. Pero aquí surge ya un problema: cuando las neuronas de una zona concreta están activas, transcurren unos tres $u$ ocho segundos para que les llegue sangre fresca enriquecida de oxígeno. Inicialmente, queda aún una gota de sangre oxigenada, precisamente porque es consumida de inmediato por las neuronas. Entonces, en unos pocos segundos, habrá disponible más sangre oxigenada de la necesaria para la actividad neuronal. Lo que significa que hay un correlato entre el flujo sanguíneo y la actividad neuronal, pero con un intervalo de tiempo entre ambos que por el momento no es posible determinar con exactitud. No es posible establecer un correlato exacto entre ambas variables. Probablemente este problema se resolverá mejor en el futuro mediante una combinación de fMRT y de una medición directa de la actividad neuronal gracias al electroencefalograma, pero no está claro hasta qué punto será posible establecer una correlación precisa entre ambos procesos. Estas observaciones conciernen únicamente a los procesos físicos del cerebro. En qué modo este aumento mínimo del flujo sanguineo puede estar vinculado a la actividad mental es una cuestión abierta.

A tenor de lo expuesto, la metáfora generalizada de la nueva imagología por ordenador a la manera de máquinas abriendo la cabeza y observando cómo el cerebro lleva a cabo sus actividades no parece especialmente útil. La comparación sugiere que somos simplemente capaces de ver lo que normalmente no podemos, asumiendo que el instrumento mismo no tiene un efecto significativo entre el observador y lo observado, el que mide y lo que es medido. La neuroimagología, según esta noción, es en esencia un órgano sensorial externo perfeccionado. Pero los instrumentos tecnológicos han sido desacreditados como órganos sensoriales externos desde el siglo XIX. No son simples asistentes de laboratorio mudos al servicio del investigador. Las técnicas de manipulación y representación transforman las cosas en objetos epistemológicamente relevantes; los instrumentos y aparatos adquieren su significado experimental en varias etapas de adaptación 
y ajuste a medida que los científicos desarrollan su pautas de actuación.

Así, la cuestión que surge es: ¿Hay o habrá algo radicalmente nuevo en el presente y futuro de las imágenes del cerebro? ¿0 estas nuevas técnicas en imagología difieren de las anteriores sólo en su grado de perfeccionamiento técnico? ¿Es la tecnología imagológica de comienzos del siglo XXI una continuación de las tecnologías desarrolladas desde el siglo XIX, cuando los dispositivos de registro redefinían los sistemas orgánicos del cuerpo? ¿0 es posible discernir una nueva neurobiopolitica que pretende definir, a través de la tecnología, la naturaleza de la mente? Sin duda alguna, la autoridad médica y cultural de las nuevas imágenes del cerebro es indiscutible. Pero, ¿qué tienen que decir sobre la naturaleza humana? Estas son las cuestiones sobre las que quisiera detenerme. En la primera parte de esta exposición haré un breve recorrido histórico sobre las imágenes del cerebro más tempranas. En la segunda parte, mostraré la diferencia existente entre las primeras imágenes del cerebro y las más recientes, y señalaré las posibles consecuencias de esta distinción.

\section{VISUALIZACIONES MORFOLÓGICAS Y FUNCIONALES DEL CEREBRO}

Para una presentación histórica de las representaciones visuales del cerebro, considero útil establecer una distinción entre las imágenes morfológicas y las imágenes funcionales del cerebro. El propósito de las primeras es capturar y representar una estructura material. Toda representación anatómica, sea el dibujo de un anatomista del siglo XVIII o una fotografía de una muestra histológica del cerebro en el siglo $\mathrm{XX}$, presupone el órgano representado como punto natural de referencia. Los anatomistas fueron muy conscientes desde el principio de que las cosas no eran tan simples: para crear una representación apropiada era preciso establecer y respetar una serie de reglas. En el siglo XVIII, era fundamentalmente una cuestión de preservación adecuada del órgano, de modo que tras ser seccionado podía ser guardado en un frasco o reproducido en un dibujo más o menos realista. Se trataba entonces de encontrar el enfoque correcto para la representación, no el del observador y dibujante fortuito, sino la mirada instruida del anatomista. Samuel Thomas Soemmerring, uno de los más importantes anatomistas de su tiempo, conocido por la gran exactitud de sus representaciones, escribió: "Es bien sabido lo difícil que resulta encontrar un dibujante que por un lado sea capaz de comprender todo lo que realmente necesita saber un disector, y por otro no sea demasiado obstinado para tomar ejemplo [...] A algunos artistas sencillamente no se les puede enseñar a ver sólo lo que realmente debe ser representado y a omitir los detalles que no pertenecen al objeto o son meramente accidentales" (Soemmerring, 1791, 5). Según Soemmerring, el anatomista no ve el cuerpo como lo hace el artista, porque sus intereses y la experiencia de cada uno son diferentes. La creación de una realidad anatómica presupone así un adiestramiento de la mirada y de la pluma.

A medida que las técnicas de la representación se vuelven más complejas, el problema de la exactitud y el riesgo de confundir un detalle artificial por un elemento natural del cuerpo se agravan. En la anatomía microscópica, por ejemplo, no sólo debía estar disciplinado el ojo, sino que el propio objeto de estudio tenía que ser sometido a una serie de complicados procesos (Chadarevian, 1994; Schickore, 2007). La visualización de células con la ayuda del microscopio dependía de diversos métodos de preparación y tintura, cada uno de los cuales hacía visibles estructuras distintas. Pero, ¿qué es lo que hacian estos métodos en realidad? ¿Seguía siendo el tejido igual de natural tras ser tratado? Si ciertas estructuras celulares se veían representadas y otras no, ¿se había obtenido una imagen fiel del sistema nervioso? Problemas de esta índole fueron predominantes a finales del siglo XIX y a comienzos del $X X$ dentro de los debates en torno a la naturaleza de las neuronas y la construcción del sistema nervioso (Breidbach, 1993, 109-115). No obstante, a pesar de todas las incertidumbres que reinaban en aquel momento, una cosa estaba fuera de duda: sólo tenía sentido observar una neurona bajo el microscopio porque era aceptada como un elemento del cerebro. Las imágenes morfológicas del cerebro siempre tuvieron un correlato natural.

Las imágenes funcionales del cerebro son también el resultado de técnicas, experimentos, hipótesis y modelos. Pero su propósito no es crear una imagen morfológica que corresponda a una estructura material. Sirven antes bien para explicar funciones, en el más amplio sentido del término, 0 indicar una asociación entre funciones y ciertas estructuras del cuerpo. No son representaciones, 
sino apuntes, diagramas o registros gráficos. Tales imágenes son por lo general consideradas como medios provisionales de clarificación y por tanto secundarios en el proceso mismo de investigación. Pero reducirlas a meras aportaciones didácticas o ilustraciones es subestimar su verdadero mérito. Las imágenes funcionales tienen una historia de su propia independencia respecto de las imágenes morfológicas, como puede advertirse en el desarrollo de la localización de las facultades mentales en el cerebro. En el siglo XIX, se hizo posible visualizar el cerebro de un modo distinto al de las imágenes morfológicas cuando se comenzó a asociar determinadas áreas del cerebro con ciertas facultades mentales. Esto significaba que tales facultades se habían convertido en objetos susceptibles de estudio científico. ¿Cómo fueron trasladadas a imágenes visuales, y cómo estas imágenes cambiaron a medida que progresó la investigación de la localización?

La representación visual de las funciones físicas y psicológicas del cerebro es tan antigua como la idea de la localización de las propiedades mentales en el cerebro. Las imágenes frenológicas en la tradición de Franz Joseph Gall proporcionaron la base para el primer mapa funcional del cerebro. Gall introdujo de manera sistemática la idea de la localización cerebral de las tendencias, talentos y propiedades mentales en las ciencias humanas al comienzo del siglo XIX, obteniendo como resultado cierta incomodidad en la época. La suposición de la existecia de órganos especiales en el cerebro para calcular, para la religiosidad, la caridad o la misericordia fue considerada por muchos contemporáneos como una amenaza para la autonomía del sujeto. La práctica popular de palpar el cráneo para elaborar el perfil de una personalidad era objeto de burla.

La figura 1 ilustra el miserable estado de la frenología, rechazada por la ciencia oficial: toda suerte de propiedades y tendencias mentales son incluidas en pequeñas celdas sobre el cráneo. Hay más órganos aquí de los que Gall jamás hubiera imaginado, pero lo más digno de destacar es la representación pictórica de las figuras, de tradición medieval y moderna (figura 2). La cabeza misma, adornada como un gorro de baño por estas inscripciones, recuerda a las cabezas de la teoria ventricular medieval, en la que las facultades (sensus communis, ratio, phantasia, memoria) aparecian inscritas a través de este tipo de bocadillos en el cerebro. Aunque la intención de Gall era completamente distinta a la teoría ventricular, la conexión visual de la

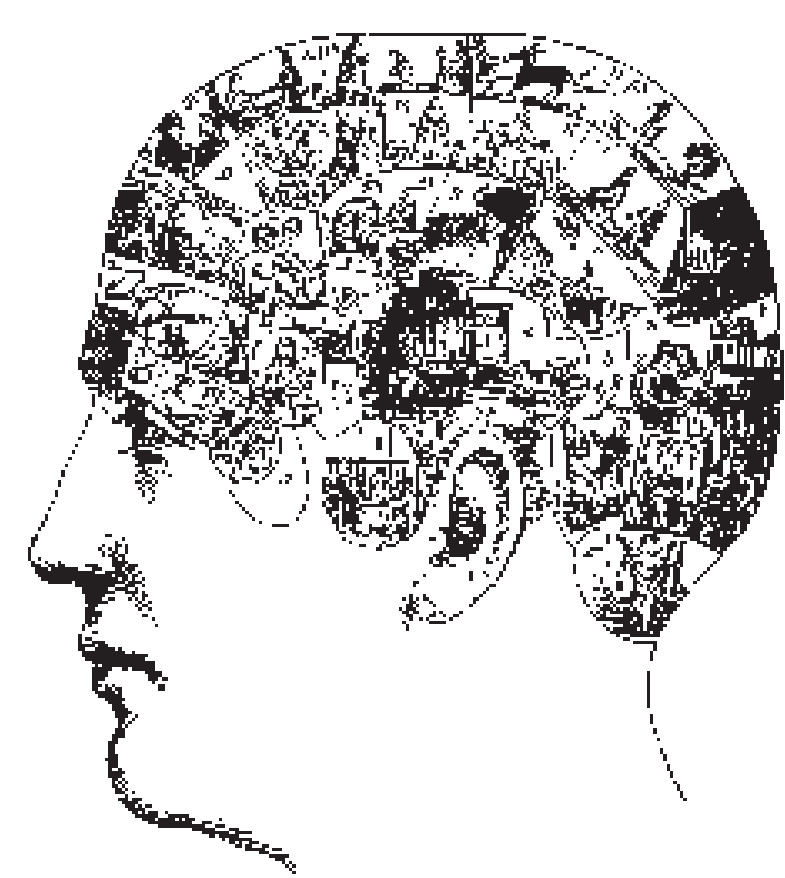

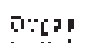

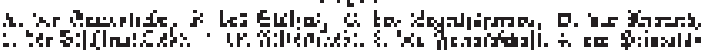

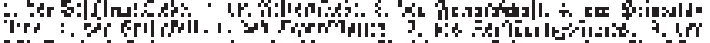
PJ' 7,

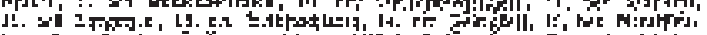

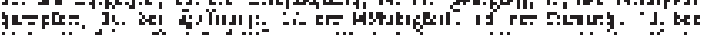

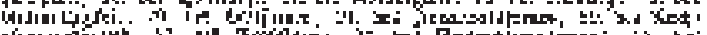

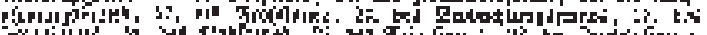

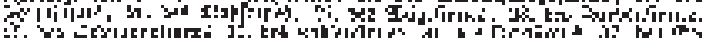

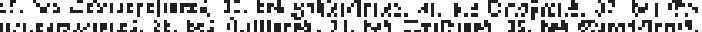

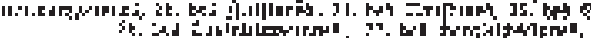

. .

Figura 1. Un mapa frenológico del cerebro.

frenología con esta tradición hizo que fuera considerada ajena al discurso científico. De este modo minó su propia reivindicación de presentar resultados de manera científica. Ninguna ciencia que se tuviera por seria habría utilizado este tipo de imágenes.

A pesar de todas las críticas a la frenología, las ideas básicas de Gall fueron desarrolladas más tarde, cuando la antropología, la biología y la medicina se convirtieron, en la segunda mitad del siglo XIX, en las principales ciencias para el estudio cuantitativo y físico del hombre. Un entramado de métodos clínicos, anatómicos y fisiológicos, de técnicas e instrumentos, se aplicó al estudio de las facultades mentales, y cada vez fue más aceptada la imagen del cerebro como un mapa en el cual se iban añadiendo suce- 


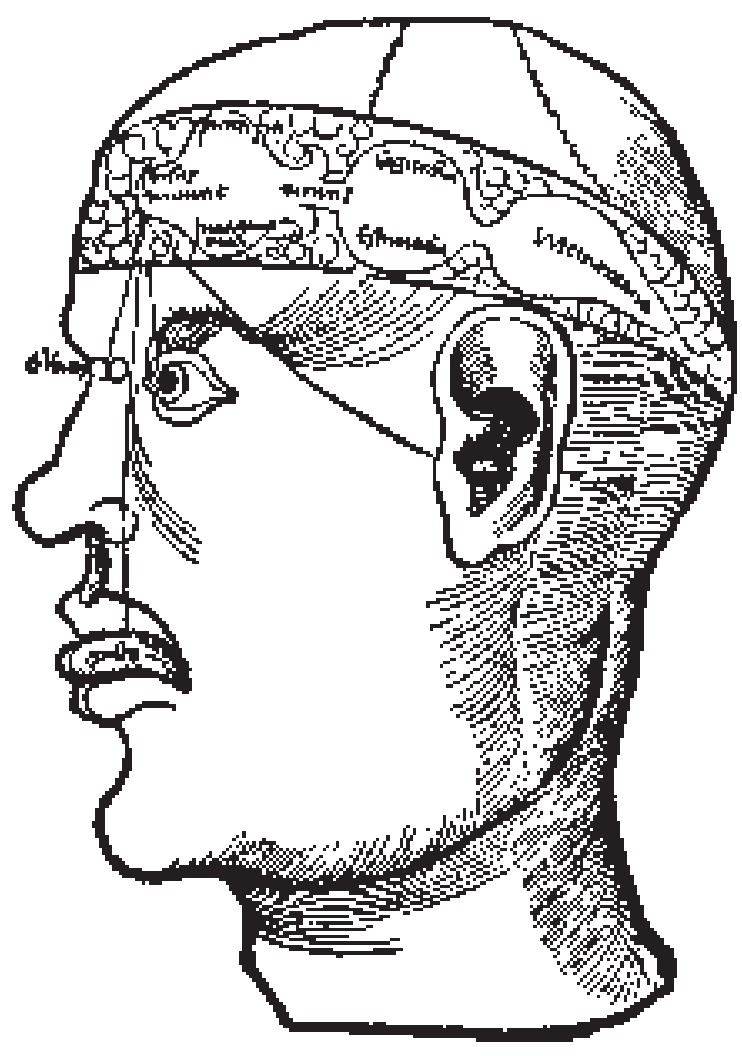

Figura 2. Mapa medieval del cerebro. Las facultades sensus communis, fantasia, aginativa, cogitativa, estimativa $y$ memoria se ubican en tres ventrículos (Gregor Reisch, Margarita philosophica, Basle 1517).

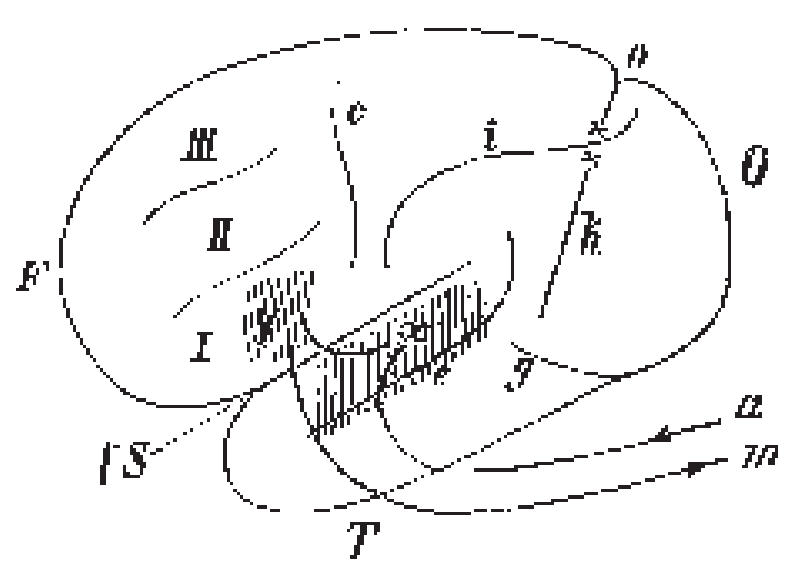

Figura 3. Representación icónica del mecanismo cerebral del lenguaje según Carl Wernicke. Para más detalles ver el texto. sivamente facultades. Las imágenes funcionales del cerebro que sirvieron como guía a este respecto eran curiosamente muy poco llamativas -al principio no eran más que bosquejos esquemáticos, cuya exactitud anatómica era sólo aproximada-. De ahí que el potencial del dibujo mostrado en la Figura 3, que localiza en el cerebro el mecanismo del lenguaje, fuera apenas apreciable. En 1874, el psiquiatra Carl Wernicke causó cierto revuelo con su teoría de la afasia, la cual sintetizaba elementos de anatomía, fisiología y patología clínica. Al centro frontal del lenguaje, donde Paul Broca había localizado el factor motriz del mecanismo del habla junto a las llamadas "imágenes del movimiento", Wernicke añadió un centro sensorial posterior que incluía además "imágenes de la memoria", con las impresiones sensoriales del pasado (Wernicke, 1874, 19). La Figura 3 describe este mecanismo cerebral: $x$ indica el centro sensorial del lenguaje, $y$ es el centro motor del lenguaje, $a x$ representa la vía auditiva, ym la vía de salida del lenguaje. Con esta representación de las funciones conectadas entre ellas, Wernicke presentaba un modelo del cerebro como máquina sensomotora. La fuerza de este modelo radicaba en el hecho de que estaba basado en estudios anatómicos y clínicos que parecian sugerir tal diferenciación funcional en la corteza cerebral. Esto llevó a que Wernicke definiera los mecanismos del lenguaje como un "arco reflejo cortical", en el que los impulsos eran recibidos, transformados y reenviados. El lenguaje no se convirtió, al menos para los propósitos estratégicos de la investigación, en algo distinto de cualquier función física, y esto es justo lo que el dibujo pretendia mostrar. Para este tipo de visualización no era necesaria la precisión anatómica en la representación de los dos centros del lenguaje.

Tras Wernicke, siguió un proceso de difusión, una búsqueda sistemática de regiones del cerebro que pudieran ser aisladas según su funcionalidad. Esta búsqueda se centró sobre todo en las propiedades que habían sido descartadas anteriormente, como la vista, el oído, o las funciones somáticas y sensoriales. Inicialmente su localización fue el objeto de una serie de experimentos planeados metódicamente. El fisiólogo berlinés Hermann Munk destacó especialmente en este sentido. Sus localizaciones en la corteza cerebral fueron más allá de la distinción topográfica de las funciones mencionadas (figura 4). Así como Wernicke había establecido una distinción entre los aspectos sensorial y motor del lenguaje, Munk distinguió, en sus experimentos sobre el sistema visual, entre la ceguera y la ceguera mental

ARBOR CLXXXVI 743 mayo-junio [2010] 435-447 ISSN: 0210-1963

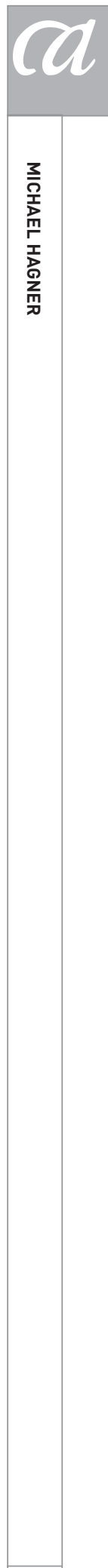

439 

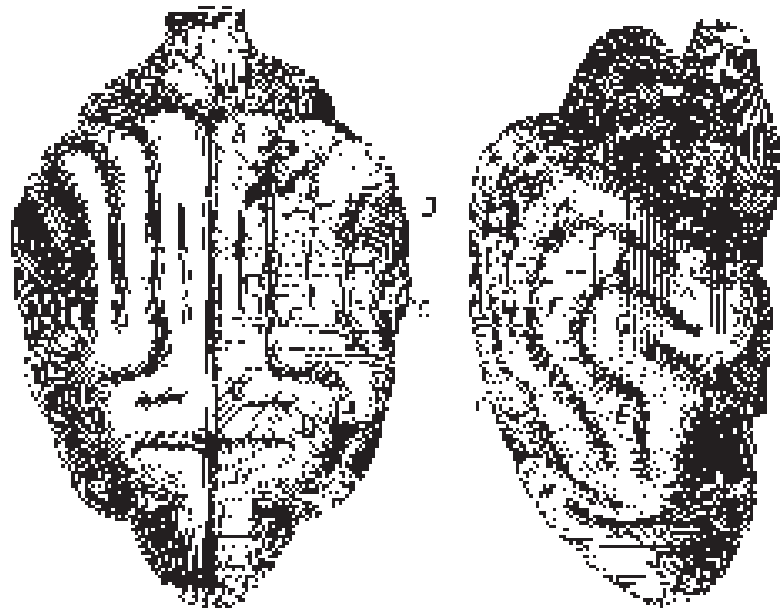

Figura 4. Descripción de Hermann Munk de la corteza cerebral de un perro: A es la esfera óptica, B es la esfera acústica, C-J son las esferas sensoriales.

("Seelenblindheit"), y en sus experimentos sobre el sistema motor y sensorial, entre la parálisis de partes concretas del cuerpo y la parálisis mental ("Seelenlähmung"). Cada una presentaba sintomas diferentes y apuntaban a lesiones en regiones cerebrales distintas. La ceguera mental hacía referencia a la ausencia de memoria visual sobre objetos familiares; la parálisis mental significaba, en el tosco lenguaje experimental de Munk, que un mono "con parálisis mental en una extremidad frontal ya no sabe cómo llevar la mano a la boca, no importa cuán grande sea su apetito hacia los manjares que tiene en las manos" (Munk, 1890, 59). Cabe destacar que no fue el comportamiento del desgraciado mono lo que encauzó la investigación de Munk. Al contrario, fue la posibilidad de representar la realidad anatómica de una región cerebral dañada lo que hizo de la conducta del mono una acción deficiente claramente identificable. Esto es lo que las figuras de Munk pretendían mostrar. Indicaban el lugar de la intervención experimental, y fueron tomadas como modelo para posteriores usos en el laboratorio.

Imágenes como éstas se encontraban muy lejos de las descripciones frenológicas sobre las representaciones mentales, aun cuando las declaraciones programáticas de la teoría de la localización apuntaran en la dirección de un estudio exhaustivo de las funciones orgánicas. La simplicidad de sus figuras ayudaron a prevenir cualquier asociación aventurada respecto a la organología de Gall. Lo mismo puede decirse del dibujo realizado por el neurólogo suizo Constantin von Monakov, a pesar de no indicar ya simplemente la localización de una intervención experimental o una lesión patológica. El objetivo de Monakov era identificar las áreas motoras en la corteza cerebral humana (figura 5), para cuyo fin recurrió a datos que procedian de muy diversas fuentes. Lo que parece ser en esta imagen una colección de datos homogéneos provenía en parte de resultados de experimentos realizados sobre animales y en parte de observaciones sobre pacientes con lesiones cerebrales (Monakov, 1897, 381). La imagen de Monakov no mostraba por tanto el cerebro de un individuo concreto, se trataba más bien de un espacio material de representación en el cual habian tenido lugar distintas técnicas científicas, algunas de ellas ni siquiera realizadas sobre el cerebro humano.

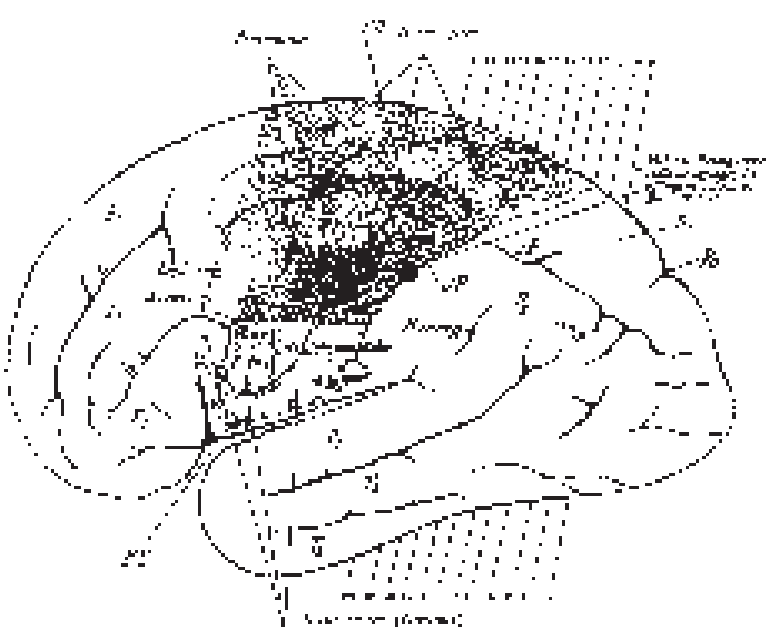

Figura 5. Descripción de la corteza cerebral de C. v. Monakov. 


\section{EL HOMÚNCULO CORTICAL}

El desarrollo de la teoría de la localización en el siglo XX no es una historia lineal de acumulación de éxitos. Las concepciones holistas en torno a una función integral del cerebro tomado en su totalidad resultaron de interés en determinadas ocasiones para la investigación del cerebro, por ayudar a resolver ciertas anomalias derivadas de la idea de localización y porque evitaban una visión reduccionista del hombre. Ajenos a tales ideas fueron los intentos posteriores de localizar las funciones motoras y sobre todo sensoriales que no eran consideradas psicológicas en el sentido estricto del término, aun cuando fueran de gran importancia a la hora de establecer la presencia icónica de las funciones mentales. La interacción de estas consideraciones puede observarse en la obra de Sigmund Freud. En su estudio prepsicoanalítico La afasia se opuso a la localización cerebral del mecanismo del lenguaje de Wernicke. Para Freud, a pesar de la innegable conexión entre la actividad mental y la anatomía de la corteza cerebral, ni la localización de las facultades mentales de Gall ni la ubicación de las propiedades psicológicas elementales de Wernicke podían escapar a la naturaleza arbitraria de la formación de los conceptos psicológicos. Estos conceptos y categorias estaban basados en observaciones de la conducta y no eran necesariamente compatibles con las complicadas leyes que regían la función cerebral (Freud, 1992, 96-7, 106-10). Por otro lado, Freud advirtió del peligro de creer que las funciones o regiones concretas de la periferia del cuerpo tuvieran una representación topográfica exacta en la corteza cerebral. Esta observación tocaba una cuestión fundamental: si cada músculo individual y cada zona particular de la piel tuviera su proyección en una ubicación precisa de la corteza cerebral, entonces, sostenía Freud, al final tendría que aparecer inevitablemente un doble cerebral de la persona misma, quizá deformado.

Hacia 1923 Freud habia cambiado su opinión. En un pasaje central de El yo y el ello, sostenía que el desarrollo del ego estaba intimamente ligado a la percepción del propio cuerpo: "El ego es en primer lugar un ego corporal; no es una mera entidad superficial, sino la proyección misma de una superficie". Consciente de que esta tesis era insostenible si no hacia referencia a la anatomía del cerebro, Freud añadía: "Si deseamos encontrar una analogía anatómica para el ego, podemos identificarlo fácilmente con el 'homúnculo cortical' de los anatomistas" (Freud, 1955, 253-4). Por aquel entonces las inscripciones anatómicas, clínicas y experimentales de funciones en la corteza cerebral se encontraban bastante avanzadas, pero la carrera del hombrecillo del cerebro no había hecho más que empezar.

Los primeros estudios experimentales fueron realizados sobre animales, pero un campo enteramente nuevo de investigación se abrió con las primeras operaciones neuroquirúrgicas. Las experiencias sobre el cerebro humano fueron realizadas en relación a la terapia quirúrgica para la epilepsia, cuya práctica estaba a la vanguardia: la estimulación eléctrica de varias regiones de la corteza cerebral durante la operación no eran experimentos adicionales, pues el propósito era localizar con exactitud el foco epiléptico. Esto permitió trazar un mapa más exacto, que a la vez permitiera intervenciones neuroquirúrgicas más efectivas y seguras. Así, la experimentación y el tratamiento terapéutico eran uno y lo mismo. Su éxito se confirmaba clínicamente por la evolución postoperatoria, y científicamente por el correlato hallado entre una estructura anatómica conocida y la ubicación de la estimulación eléctrica (Hagner, 1994). El neurólogo y neurocirujano de Breslau Otfried Foerster fue capaz de dibujar un mapa con todas las áreas de proyección sensorial y motora en la corteza cerebral (Foerster, 1925).

Los resultados obtenidos a través de la estimulación directa sobre personas vivas permitían a Foerster introducir una serie de funciones en una misma sección del mapa cerebral: "los movimientos rítmicos al masticar, salivar, tragar, relamerse, gruñir, bramar, gimotear" (ibid., 539-40). Los experimentos provocaban artificialmente actos involuntarios que en condiciones normales estaban controlados mínimamente por la voluntad del sujeto. Los pacientes de Foerster estaban despiertos durante la operación, pero no eran más que indefensos objetos de las sucesivas estimulaciones eléctricas. Sometidos a estimulaciones en la región parietal de la corteza cerebral, se esperaba que experimentaran sensaciones como la de "flotar, cosquilleo, sensaciones eléctricas, sensaciones de ahogo, fatiga muscular" (ibid., 543). En estos experimentos realizados por Foerster, la técnica anatómica de la citoarquitectónica mostró ser muy efectiva en dos aspectos: en primer lugar como apoyo metodológico para la cirugía del cerebro, que al fin presentaba alguna promesa de éxito, y en segundo lugar como representación de la maquinaria psicológica del cerebro, la reconstrucción completa de lo que era la 
meta de la investigación del cerebro. Pero las imágenes visuales eran además la expresión de la voluntad de verdad en la investigación sobre el cerebro. Pues las imágenes funcionales del cerebro se habían convertido ahora en algo más que un simple modo de indicar la localización obtenida de la manipulación del investigador: presentaban verdades sobre el cerebro y, por ende, sobre el ser humano (figura 6).

No pasaron más que unos pocos años para que apareciera una oportuna confirmación visual de esta reivindicación. El neurocirujano canadiense Wilder Penfield se familiarizó con la técnica de la estimulación intraoperativa de la corteza cerebral durante una estancia de investigación con Foerster en Breslau. Penfield tenía mejores técnicas a su disposición y un número mucho mayor de pacientes a quienes poder realizar las operaciones. Asi, fue capaz de modificar y mejorar la representación cerebral de Foerster, y dedujo que las proyecciones sensomotoras en la corteza cerebral mostraban que el ser humano era un ser concentrado en los pulgares, los labios y la lengua. La representación del ser humano como un pequeño homúnculo (figura 7) formado por las partes separadas del cuerpo indicaba una nueva etapa en la representación de las cualidades psicofísicas, en las que una persona se hacía visible, a la manera exacta de la prognosis de Freud. La deformación en el homúnculo de Penfield mostraba cómo era entonces la delegación estructural de las funciones, lo constitutivo al ser humano. Las representación con formas prominentes de regiones del cuerpo como los pulgares, los labios y la lengua, indicaba que ocupaban más espacio en el cerebro, en proporción a su importancia sensorial y motora en el mundo real (Penfield and Rasmussen, 1950, 114-5). Un icono como el homúnculo sugería que los investigadores del cerebro eran capaces de desmontar al hombre y volverlo a montar, aunque al final pareciera algo distinto a lo que antes era. Lejos de ser un mero divertimento, el homúnculo es la visualización de décadas de investigación experimental.

Este breve recorrido, que abarca el período comprendido entre la organología de Gall y el homúnculo de Penfield, muestra cómo mientras los conceptos y prácticas antropológicos y psicológicos evolucionaron, la pretensión de comprender la vida mental humana a través de medios cuantitativos no lo hizo. A Gall le preocupaba dividir al hombre en propiedades, deseos, tendencias y talentos. Más

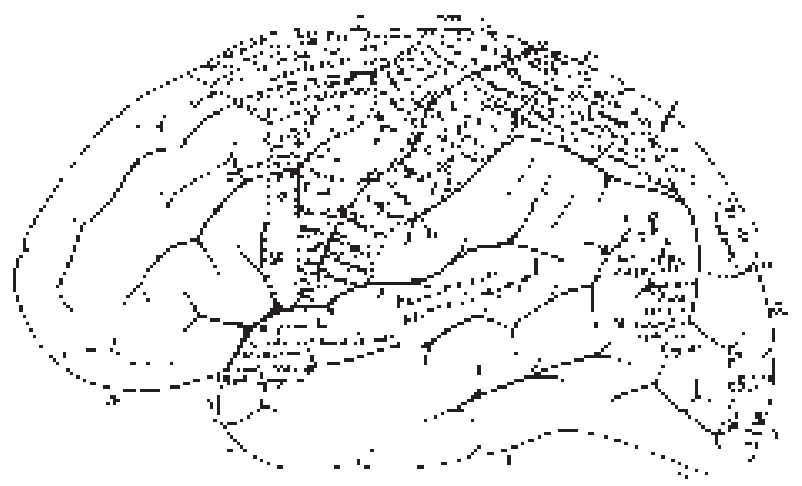

Figura 6. La representación cerebral de los centros motor y sensorial según Otfried Foerster.
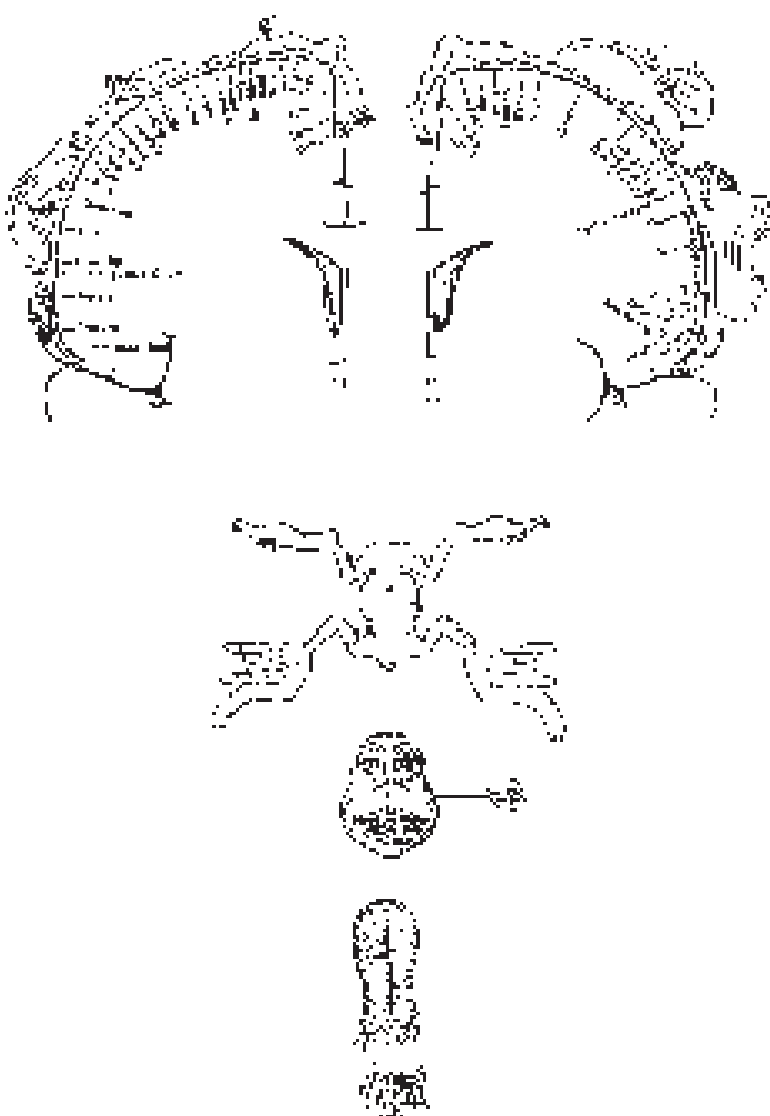

Figura 7. Arriba: Representación de las regiones sensorial (izquierda) $y$ motora (derecha) sobre la corteza cerebral; Abajo: transformación figurada de las regiones corticales en un homúnculo (según Wilder Penfield). 
tarde se trató de dividir al hombre en funciones psicológicas y físicas. Las imágenes funcionales del cerebro usadas en la investigación de la localización estuvieron siempre presentes durante este periodo, ya fuera como apoyo heurístico o como representación de las cualidades mentales o del hombre mismo.

A menudo ocurre que la ciencia no aborda su propia historia con suficiente rigor. La historia del progreso científico se altera para que la investigación vigente encaje con las clasificaciones históricas. Tras alcanzar un lugar bien asentado en el conocimiento de los libros de texto e influir en la estrategia de la investigación del cerebro durante varias décadas, con una avalancha de representaciones gráficas del cerebro en su haber, el homúnculo de Penfield terminó siendo desacreditado como naif y erróneo. En un artículo del influyente Journal of Neurology, Neurosurgery and Psychiatry, Penfield fue acusado de haber abusado del homúnculo pasando por alto la falta de precisión metodológica en sus resultados -como por ejemplo mediciones no contrastadas sobre grupos de pacientes, una inadecuada determinación funcional de determinadas regiones, o el fracaso a la hora de diferenciar diversas localizaciones o tipos de estimulación- y por consiguiente también de haber traspasado la frontera que separa al hecho de la ficción: "Con el homúnculo, la ciencia ha cedido el paso a la filosofía" (Schott, 1993, 333). En otras palabras, el valor científico del homúnculo fue puesto en duda, y hoy en día no es ya considerado ni útil ni válido. No es accidental que esta nueva consideración tenga lugar en un momento en el que los historiadores han estudiado el homúnculo como símbolo tangible de las pretensiones de explicar al hombre en su totalidad, y cuando puede ser admirado en grandes exposiciones en torno a la historia de la investigación sobre la mente humana, adquiriendo finalmente el estatus de una "semiófora" (Pomian, 1997) culturalmente establecida. Mientras tanto, la neuroimagología ha producido nuevos ídolos icónicos. El homúnculo cumplió con sus propósitos. Ya puede marcharse.

A la luz de estas pinceladas históricas podemos preguntarnos en qué sentido estas imágenes, apuntes y esquemas que acabamos de ver, incluyendo el homúnculo de Penfield, están relacionadas con las actuales imágenes por ordenador, con su contenido morfológico y su producción técnica. La respuesta es simple: no hay relación alguna. Ha perdurado la intención de hallar una solución científica a la vieja cuestión filosófica mente-cuerpo, y la concepción del cerebro como un espacio material de representación se ha conservado desde el comienzo de la investigación sobre la localización. Pero la principal división entre las imágenes morfológicas y funcionales ya no tiene sentido. A partir de la segunda mitad del siglo $X X$, cuando las técnicas aún vigentes como la tomografía por ordenador representan estructuras y los impulsos nerviosos se han hecho visibles, sobre todo a través de la técnica de desviación y los registros gráficos del electroencefalograma, la división se ha vuelto obsoleta con las nuevas técnicas de visualización.

\section{Neuroimagología: la fisionomía INTROSPECtiva}

En la medida que el conocimiento de las funciones cerebrales y sus ubicaciones se basa cada vez más en la neuroimagología, el problema epistemológico que surge es: ¿Qué significa, entre otros aspectos, que una determinada actividad mental corresponda con una determinada imagen del cerebro? ¿Qué significa corresponder en este caso, qué significa representar? A la luz del tremendo poder de las imágenes, ¿Seguirá sirviendo la construcción simbólica del cuerpo como respuesta a la pregunta "Qué es el hombre"? ¿0 se desarrollará un nuevo vocabulario para explicar nuestro acceso a través del cerebro hacia nosotros mismos y hacia el mundo? ¿Cómo cambiará nuestra percepción de nosotros mismos en tanto que humanos capaces de viajar hacia nuestro interior, no sólo mediante un endoscopio insertado por los orificios naturales del cuerpo, sino a través de nuestros propios cerebros? ¿Cómo? ¿Siendo capaces de observarnos por partida doble: mediante el pensamiento introspectivo y las sensaciones, y observando después las correspondientes alteraciones del cerebro en la pantalla del ordenador? Semejantes planteamientos arrojan luz sobre una nueva forma de biopolítica. Es ya casi una realidad que los escáneres del cerebro se conviertan en un medio de exteriorizar nuestro más íntimo ser de un modo tal que, en comparación, los detectores de mentiras parezcan meros confesores indulgentes.

Hace quince años, John Taylor, director del Centro para las Redes Neuronales en el King's College de Londres, declaró: "Se abren ventanas hacia la mente por toda la materia gris" (Taylor, 1994, iv-v). Este es uno de los más tempranos ejemplos de jactancia retórica que terminó siendo un 
factor determinante en la percepción pública de la neuroimagología. Un elemento central en este tipo de puesta en escena fue el refuerzo mutuo entre la palabra y la imagen. Hacia la mitad de la página, próximo al título del artículo de Taylor hay una amplia imagen a color con una resplandeciente bola de fuego sobre una esfera deformada y atravesada por surcos que se vuelve más oscura hacia los bordes, con un fondo negro de contraste. A decir verdad, la imagen parece un logotipo del MRT. La bola de fuego representa la región activa del cerebro de un voluntario que empieza a pronunciar una palabra para sus adentros. Una imagen del cerebro como ésta, señala Taylor, ofrece "un enfoque mucho más concreto" de la mente. Su artículo arremete contra las ideas de conciencia y autoconciencia como si se tratara del frente enemigo, y da la sensación de que el problema sobre el modo en que el cerebro da lugar a los procesos mentales puede ser pronto resuelto. Michael Posner y Marcus Raichle, dos pioneros en la neuroimagología, han manifestado un sentimiento parecido en su libro Images of Mind, cuyo propio título mantiene ya la promesa de hacer visible algo que usualmente se considera imposible de visualizar. Las imágenes del libro son algo obsoletas, pues es ya posible representar el flujo sanguíneo con mucha más precisión mediante el BOLD-fMRT, pero esto no cambia su pretensión de presentar nuevos mundos cerebrales, "los sistemas cerebrales que intervienen cuando pensamos" (Posner and Raichle, 1994, 245).

Mientras los frenólogos estudiaban partes muertas del cráneo o del cerebro, las nuevas visualizaciones del cerebro en vivo lo hacen sobre lo que percibimos como un yo pienso o un yo siento. Todas las imágenes del cerebro de las nuevas neurociencias cognitivas poseen un importante aspecto fisionómico. Podemos observar cómo funciona la mente a través de la mera observación del rubor o la mímica de un rostro y a partir de ahí trazar conclusiones sobre el estado de la persona en cuestión. La neuroimagología es entonces una especie de fisionomía introspectiva. ¿Qué es lo que quieren decir los neurocientíficos cuando proclaman que mediante el acceso a los procesos neuronales las nuevas técnicas en imagología son capaces de producir una visualización cada vez más perfecta de la actividad mental? En primer lugar, la vieja idea de la localización, según la cual una facultad estaba asociada a una región particular, se aplica ahora a una red mucho más compleja. Nadie duda de la existencia de los centros motores y sensoriales del lenguaje. Pero las cuestiones a las que responden las investigaciones presentes y futuras son: ¿Qué áreas del cerebro están activas durante el proceso de una tarea lingüistica concreta, qué parte de la tarea se lleva a cabo en qué lugar; cómo se relacionan entre sí las diferentes redes neuronales? A medida que va progresando la investigación, no parece tan utópico imaginar la posibilidad de insertar, por ejemplo, en un individuo todos los procesos mentales necesarios para el cálculo, para jugar al ajedrez, componer música, realizar algún trabajo artesano, leer, o ver imágenes morfológicas o funcionales del cerebro en tres dimensiones. Se ha hecho posible representar la diferente actividad cerebral resultante de la percepción de una cara conocida y la de una cara desconocida. Esta destreza puede ser de gran interés para la policía secreta 0 militar. Sin embargo, ¿será alguna vez posible leer el perfil de una persona como si de un curriculum vitae o un apunte autobiográfico se tratara, con la excepción de que el autor no es ya el individuo que reflexiona sobre sí mismo, sino la representación visual de una actividad cerebral que puede ser localizada en el espacio y el tiempo?

Imaginemos un jugador de ajedrez meditando su próximo movimiento. Su concentración se hace evidente en su postura y su expresión facial. Pero no son poses específicas del juego del ajedrez ni dicen nada del contenido del proceso mental. La imagen cerebral que muestra la mente en plena actividad da otros resultados. La fisionomía del cerebro, la imagen de la actividad que acompaña a la reflexión del jugador sobre su próximo movimiento, es específica en el sentido de que puede distinguirse de otras actividades mentales. Además, la actividad es cuantificable, al menos para tareas de un mismo tipo o semejantes: lo que para uno es el titileo de una vaga luz para otro es una antorcha resplandeciente. Es posible establecer conclusiones de tales diferencias. Aun asumiendo que este tipo de datos no son siempre accesibles, resulta concebible que el perfil cerebral de un individuo se utilice en el proceso selectivo de profesiones con cierto grado de dificultad o riesgo, o para cubrir puestos de responsabilidad. Quizá esto sólo pudiera darse junto a tests psicológicos, los cuales no desaparecerán tan pronto como creemos. Pero se podría descartar la posibilidad de que en ciertos dominios las imágenes del cerebro pudieran convertirse en elementos rutinarios, como lo es el electrocardiograma en la diagnosis de las enfermedades del corazón y de la circulación. Esto podría ser ante todo una cuestión de viabilidad técnica, administrativa y de financiación. Es cierto que tanto el 
encefalograma como otros métodos de examen utilizados desde hace tiempo no se han hecho rutinarios en la determinación y optimización de resultados. Pero esto se ha debido principalmente a su escaso valor en comparación con otras fuentes de información sobre el funcionamiento del cerebro. Por el contrario, el electrocardiograma ha jugado en las pasadas décadas un considerable papel en la determinación de la disposición para trabajar, tomarse unas vacaciones, hacer deporte o amar. En rigor los electrocardiogramas proporcionan información sobre el funcionamiento del corazón, pero en un sentido más amplio contribuyen sustancialmente a determinar el perfil del rendimiento físico de una persona.

Para algunos, las nuevas técnicas en imagología deben trabajar con la esperanza de elaborar una especie de perfil mental. ¿Sobre qué podría arrojar luz tal hiperfisionomía? El pensamiento desordenado puede distinguirse de la resolución de problemas matemáticos, reconocer el rostro de un familiar lo hace respecto a entonar una canción para los adentros, recordar las primeras experiencias de la infancia respecto a la primera discusión con la pareja, el conflicto con los padres respecto a los sueños eróticos. ¿Qué se gana con estas distinciones? La respuesta no se halla ni en el cerebro ni en las máquinas y por tanto no puede determinarse ni cerebral ni técnológicamente. Más bien puede hallarse sólo en el ámbito de las negociaciones sociales y culturales que determinan lo que ha de significar esta información sobre el cerebro.

En el siglo XX la investigación sobre la psique humana era tarea del psicoanálisis principalmente. Ningún escáner del cerebro puede igualar los detalles biográficos, las intimidades y los más ocultos estratos de la personalidad desvelados por el psicoanálisis. Pero lo crucial se halla en otro lugar. El psicoanálisis tuvo ciertas repercusiones, pero nunca se convirtió en un método recurrente para la biopolítica. Supongo que no es porque los presupuestos del psicoanálisis hayan sido considerados aberrantes, ni porque el inconsciente o los deseos humanos no hayan tenido un buen recibimiento en la ingeniería social. Es mucho más probable que la cuestión radique en que el psicoanálisis ha resultado demasiado elitista y complicado, demasiado tedioso, impracticable y difícil de manejar. Sus resultados no son lo bastante elementales y sí demasiado complejos para resultar operacionales en una determinación general de perfiles de personalidad.
Las imágenes del cerebro son mucho más apropiadas para este propósito. Muestran aspectos mucho menos complejos de la personalidad y son por tanto más fácilmente adaptables a propósitos biopolíticos. Las imágenes del cerebro podrian servir para inscribir normas, consultar, controlar, hacer sugerencias, proporcionar pautas para la autoevaluación y planes de acción. Así como un electrocardiograma advierte si un paciente que ha sufrido un ataque al corazón está recuperado para el ajetreo del acto sexual, las imágenes del cerebro determinarian si alguien está más dotado para la música o para las matemáticas. Por supuesto, una sola imagen no es suficiente para tal propósito. En el transcurso de un determinado período de tiempo, imágenes adicionales podrian dar cuenta de los progresos y ser grabadas en chips de datos personales, listos para ser consultados en cualquier momento y lugar. Un aumento de lucidez en la imagen cerebral de un estudiante podría servir de motivación en su aprendizaje, del mismo modo que una imagen de rayos $X$ le muestra a un paciente que su hueso roto se está recuperando. El punto de referencia para la valoración de tales imágenes pueden ser las imágenes grabadas con anterioridad.

Avances de este tipo podrían conducir a una situación en la cual la diversidad y relevancia de la vida mental se midieran principalmente por su visualización. De acuerdo con Vilém Flusser, las nuevas imágenes nos "permiten dejar atrás una vez más el vago mundo de las abstracciones y volver a la experiencia concreta, al conocimiento, al juicio y a la acción" (Flusser, 1992, 44). Pero este desarrollo tiene un precio: "la búsqueda de conexiones más profundas, explicaciones, enumeraciones, recuentos y cálculos, esto es, el pensamiento lineal y textual con un enfoque histórico y científico, ha sido reemplazado por un modo de pensar superficial vinculado a la imagen". En las ciencias humanas, el pensamiento y la profundización a la antigua usanza, del cual el psicoanálisis puede considerarse representativo, está siendo reemplazado por el conocimiento superficial de las imágenes del cerebro -sin preocuparse por la validez o invalidez del enfoque anterior-. El estudio de los seres humanos podria limitarse entonces a producir formas materiales de representación como churros. No se trata del problema de la abolición del sujeto sino del advenimiento de una nueva antropología: una antropología cerebral que en realidad no produce ya nada más que estructuras superficiales.

ARBOR CLXXXVI 743 mayo-junio [2010] 435-447 ISSN: 0210-1963

(n)


Una de las consecuencias de este nuevo desarrollo podría ser que la introspección y las interpretaciones subjetivas se fueran quedando en el camino. Algunos investigadores del cerebro ya han recomendado alguna vez evitar tales categorías. El difunto Francis Crick consideró desproporcionada esta hipótesis según la cual "para conocernos a nosotros mismos necesitamos comprender el comportamiento y la interacción de las neuronas" (Crick, 1994, 10). Este punto de vista no es precisamente nuevo, pero mientras en los primeros tiempos los investigadores del cerebro se retiraban adoptando en cierta medida posiciones de escepticismo o agnosticismo, ahora la alegría y el sufrimiento, la intencionalidad, la identidad y el libre albedrío son considerados como "el comportamiento de un gran número de neuronas y sus moléculas" (ibid., 17).

Es inevitable que concibamos el aumento mínimo del flujo sanguíneo en una determinada región del cerebro como el correlato o la causa de un esfuerzo mental, de la declamación de un poema o de los pensamientos y sensaciones que acompañan a la contemplación de una imagen fotográfica o un rostro transfigurado. Qué se obtiene con ello es una cuestión cuya respuesta difícilmente se hallará en las meras imágenes.

\section{NOTAS}

1 Una versión anterior de este artículo en alemán fue publicada en Anatomien medizinischen Wissens, C. Borck (ed.), 259-286. Frankfurt a. M.: S. Fischer 1996. Desde entonces he revisado en cierta medida mi opinión. Cuando escribí la primera versión de este texto en 1995 bajo el impacto del potencial técnico de la neuroimagología, estaba bastante seguro de que ésta podría cambiar fundamentalmente la manera de vernos a nosotros mismos. Ahora ya no estoy tan seguro. Las imágenes son nuevas, pero no las interpretaciones propuestas para dar sentido a lo que muestran. Esto es algo que no habria esperado entonces. Entre los estudios que se han publicado posteriormente sobre este tema, ver Hagner 2002; 2004; 2006; Dumit 2004; Weigel 2004; Burri 2008.

\section{REFERENCIAS}

Recibido: 1 de diciembre de 2008

Aceptado: 1 de mayo de 2009
Barthes, Roland (1981): Camera Lucida: Reflections on Photography, New York, Farrar Straus and Giroux.
Blume, Stuart S. (1992): Insight and Industry: On the Dynamics of Technological Change in Medicine, Cambridge, MA, MIT Press.

Breidbach, Olaf (1993): Nervenzellen oder Nervennetze? Zur Entstehung des Neuronenkonzepts. En: Das Gehirn - Organ der Seele? Zur Ideengeschichte der Neurobiologie, ed. Ernst Florey y Olaf Breidbach, 81-126, Berlin, Akademie.

Burri, Regula Valerie (2008): Doing Images. Zur Praxis medizinischer Bilder, Bielefeld, Transcript.

Cartwright, Lisa (1995): Screening the Body: Tracing Medicine's Visual Culture, Minneapolis, University of Minnesota Press.

Chadarevian, Soraya de (1994): Sehen und Aufzeichnen in der Botanik des 19. Jahrhunderts. En Der Entzug der Bilder. Visuelle Realitäten, ed. Michael Wetzel y Herta Wolf, 121-44, Munich, Fink.

Crick, Francis (1994): Was die Seele wirklich ist. Die naturwissenschaftliche Erforschung des Bewusstseins, Munich, Artemis.

Dommann, Monika (2003): Durchsicht, Einsicht, Vorsicht: Eine Geschichte der Röntgenstrahlen, 1896-1963, Zurich, Chronos. 
Dumit, Joseph (2004): Picturing Personhood: Brain Scans and Biomedical Identity, Princeton, Princeton University Press.

Flusser, Vilém (1992): Ins Universum der technischen Bilder, 4th ed., Göttingen, European Photography.

Foerster, Otfried (1925): Zur Pathogenese und chirurgischen Behandlung der Epilepsie, Centralblatt für Chirurgie, 25: 531-56.

Freud, Sigmund (1955): Das Ich und das Es [1923]. En idem: Gesammelte Werke. Vol. 13, 3rd ed., London, Imago.

Freud, Sigmund (1992): Zur Auffassung der Aphasien [1891], Frankfurt a. M. Fischer.

Hagner, Michael (1994): Lokalisation, Funktion, Cytoarchitektonik. Wege zur Modellierung des Gehirns. En Objekte, Differenzen und Konjunkturen, ed. Michael Hagner, Hans-Jörg Rheinberger y Bettina Wahrig-Schmidt, 121-50, Berlin, Akademie.

Hagner, Michael (2002): "Cyber-Phrenologie. Die neue Physiognomik des Geistes und ihre Ursprünge", en Die Politik der Maschine, ed. Klaus Peter Dencker, 182-98, Hamburg, Verlag Hans-Brednow-Institut.
Hagner, Michael (2004): Geniale Gehirne. Zur Geschichte der Elitegehirnforschung, Göttingen, Wallstein.

Hagner, Michael (2006): Der Geist bei der Arbeit. Historische Untersuchungen zur Hirnforschung, Göttingen, Wallstein.

Hüsing, Bärbel, Jäncke, Lutz, y Brigitte Tag (2006): Impact Assessment of Neuroimaging, Zürich, IVT Verlag.

Penfield, Wilder y Theodore Rasmussen (1950): The cerebral cortex of man. A clinical study of localization of function, New York, Macmillan.

Munk, Hermann (1890): Über die Functionen der Grosshirnrinde. Gesammelte Mitteilungen, 2nd ed., Berlin, Hirschwald.

Monakov, Constantin von (1897): Gehirnpathologie, Wien, Hölder.

Pomian, Krzysztof (1997): Der Ursprung des Museums. Vom Sammeln, 3rd ed., Berlin, Wagenbach.

Posner, Michael I. y Marcus E. Raichle (1994): Images of Mind, New York, Scientific American Library.

Roth, Gerhard (1994): Braucht die Hirnforschung die Philosophie? En Neuroworlds. Gehirn - Geist - Kultur, ed. Jutta Fedrowitz, Dirk Matejovski, and Gert Kaiser, 81-92, Frankfurt a. M., Campus.
Schickore, Jutta (2007): The Microscope and the Eye: A History of Reflections, 1740-1870, Chicago, University of Chicago Press.

Schott, G. D. (1993): Penfield's homunculus: a note on cerebral cartography, Journal of Neurology, Neurosurgery and Psychiatry 56: 329-333.

Soemmerring, Samuel Thomas (1791): Abbildungen und Beschreibungen einiger Misgeburten, Mainz, Universitätsbuchhandlung.

Taylor, John (1994): Windows open on the mind over grey matter, The Times Higher Education Supplement, Multimedia December 9: iv-v.

Weigel, Sigrid (2004): "Phantombilder zwischen Messen und Deuten. Bilder von Hirn und Gesicht in den Instrumentarien empirischer Forschung von Psychologie und Neurowissenschaft", en Repräsentationen. Medizin und Ethik in Literatur und Kunst der Moderne, ed. Bettina von Jagow y Florian Steger, 159-99, Heidelberg, Winter.

Wernicke, Carl (1874): Der aphasische Symptomencomplex. Eine psychologische Studie auf anatomischer Basis, Breslau, Cohn \& Weigert. 